\title{
Síndrome hemofagocítico asociado con dengue hemorrágico
}

\author{
Ernesto Rueda, Angela Méndez, Gerardo González \\ Departamento de Pediatría, Universidad Industrial de Santander, \\ Hospital Universitario Ramón González Valencia, Bucaramanga, Colombia.
}

El síndrome hemofagocítico se caracteriza por proliferación histiocítica con fagocitosis de células hemáticas que ocasionan citopenia. Ha sido relacionado antes con diversas infecciones, principalmente por virus. Informamos de tres pacientes con síndrome hemofagocítico secundario a dengue hemorrágico, confirmado por exámenes específicos de laboratorio, quienes fueron internados en el Hospital Universitario Ramón González Valencia de Bucaramanga, Colombia, durante los últimos dos años. Los tres pacientes fueron escolares que presentaron dengue hemorrágico y manifestaron dolor abdominal intenso, fiebre prolongada, hipotensión y hepatomegalia dolorosa; los exámenes paraclínicos mostraron plaquetopenia, anemia y leucopenia; en la ecografía abdominal se observó colecistitis acalculosa y en todos los aspirados de medula ósea se encontraron histiocitos fagocitando células hemáticas de la serie eritroide, mieloide o plaquetaria. Se definió y clasificó el síndrome hemofagocítico, según la Sociedad Internacional de Histiocitosis, en tres grandes clases, recalcando que los casos informados corresponden a histiocitosis clase II y, más específicamente, al síndrome hemofagocítico secundario. Se mencionan las diversas asociaciones de este síndrome con infecciones, principalmente virales, y otras enfermedades no infecciosas; se hace diferenciacion entre síndrome hemofagocítico familiar o primario y el secundario. Finalmente, se enfatiza que los tres pacientes con este síndrome asociado con dengue hemorrágico tuvieron una evolución atípica durante el curso de su enfermedad; la fiebre prolongada y el dolor abdominal persistente fueron los síntomas más importantes. Los autores recomiendan realizar un aspirado de médula ósea como parte de los estudios para el diagnóstico diferencial de casos atípicos de dengue, especialmente con fiebre prolongada, buscando la posibilidad de un síndrome hemofagocítico secundario.

Palabras clave: dengue, dengue hemorrágico, síndrome hemofagocítico.

\section{Haemophagocytic syndrome associated to dengue haemorrhagic fever}

The haemophagocytic syndrome is characterised by systemic proliferation of non-neoplastic histiocytes showing haemophagocytosis resulting in blood cytopaenia. It has been described in relation to several viruses earlier. We present three patients with haemophagocytic syndrome (HFS) secondary to dengue haemorrhagic fever (DHF) confirmed by standard laboratory tests. The patients were hospitalized at the University Hospital (Hospital Universitario Ramon Gonzalez Valencia-HURGV) in Bucaramanga, Colombia, during the past two years. They were all school-aged patients who presented DHF with intense abdominal pain, prolonged fever, hypotension and painful hepatomegaly. Laboratory tests showed thrombocitopenia, anaemia and leucopenia. A calculous cholecystitis was observed in the abdominal ultrasonography, and all bone marrow aspirations showed that platelets, red and white blood cells were phagocyted by histiocites. According to the International Society of Histiocytosis, SHF is defined and classified in three major categories; the reported cases corresponded to histiocytosis class II, specifically to secondary SHF. Diverse associations of this syndrome correspond to viral infections and some other non-infectious diseases. A difference has been established between primary SHF and secondary SHF. Finally, we emphasize that these three patients had an atypical evolution of FHD, being prolonged fever and persistent abdominal pain the most important symptoms. The authors recommend that a bone marrow aspiration should be carried out as part of the differential diagnosis study in prolonged fever associated with dengue, as there is a possibility that this complication could be secondary SHF.

Key words: dengue, dengue haemorrhagic fever, haemophagocytosis. 
Las infecciones por el virus del dengue causan un espectro muy amplio de manifestaciones clínicas que van desde el dengue clásico benigno hasta el dengue hemorrágico, el cual puede llegar al choque y producir la muerte. También se pueden presentar manifestaciones poco usuales como alteraciones neurológicas y hepáticas o en otros órganos como la vesícula biliar, el páncreas, el corazón, los riñones, etc. $(1,2)$. Entre las manifestaciones poco usuales sólo hay dos informes de síndrome hemofagocítico asociado con el dengue $(3,4)$. El síndrome hemofagocítico se caracteriza por la proliferación histiocítica con fagocitosis de células hemáticas que ocasionan citopenias. El presente estudio informa tres casos de pacientes que presentaron síndrome hemofagocítico secundario a dengue hemorrágico. Todos los casos fueron confirmados por el Laboratorio Departamental mediante ELISA-IgM para dengue. No se hicieron exámenes para identificar el virus, pero en las zonas de procedencia de los pacientes se identificaron los serotipos Den-1, 2 y 4 durante el mismo período (5).

Bucaramanga es una ciudad situada en los Andes colombianos a $1.000 \mathrm{~m}$ sobre el nivel del mar, con 1'000.000 de habitantes, en la cual se han presentado gran cantidad de casos confirmados de dengue hemorrágico desde 1992, de los cuales más de 700 , todos niños, han sido atendidos en el Departamento de Pediatría del Hospital Universitario Ramón González Valencia (HURGV), procedentes de áreas urbanas de Bucaramanga y municipios vecinos. En el seguimiento de estos casos encontramos los pacientes objeto del presente informe.

A continuación se describen los tres casos de pacientes que presentaron síndrome hemofagocítico, los cuales se encontraron entre julio de 1999 y agosto de 2000, en el marco del seguimiento que hemos venido haciendo de pacientes con fiebre hemorrágica por dengue

Correspondencia:

Gerardo González

Teléfonos (577) 6350109 y 6389404

Fax (577) 6389422

gergon@uis.edu.co o gergon@telebucaramanga.net.co

Recibido: 11/12/01; aceptado: 24/05/02 desde 1992 en el HURGV, y que presentaron como manifestación inusual fiebre prolongada. Se descartaron otras causas frecuentes en nuestro medio de fiebre prolongada de origen desconocido.

\section{Caso 1}

Paciente de 11 años, de sexo masculino, hospitalizado del 16/07/99 al 10/08/99. Consultó por sintomatología aguda de fiebre, cefalea, osteomialgias, astenia, adinamia y dolor abdominal. Al hacer el examen físico inicial presentaba epistaxis, hepatomegalia dolorosa y desnutrición aguda leve. Durante la hospitalización, la fiebre se prolongó durante tres semanas; en la primera semana se complicó con deshidratación e hipotensión, marcado dolor abdominal y signos de irritación peritoneal. Los exámenes paraclínicos realizados fueron: múltiples hemogramas que mostraron anemia, la cual varió de 7,8 a 6,4 de hemoglobina; los leucocitos oscilaron entre 9.500 y 17.000 con predominio de neutrófilos; el recuento plaquetario varió de plaquetopenia moderada a leve (valor mínimo de plaquetas $68.000 / \mathrm{mm}^{3}$ ) y se normalizó al final de la primera semana; los reticulocitos variaron de 1,1 a $4,6 \%$; la PCR y la VSG estuvieron elevadas; la gota gruesa, los antígenos febriles y el tiempo de protrombina fueron normales; la fosfatasa alcalina estuvo elevada (467 U); el examen parcial de orina normal dio un nivel de ferritina de $103 \mathrm{ng} / \mathrm{ml}$; las radiografías de tórax y abdomen fueron normales; el TAC cerebral fue normal; la ecografía abdominal mostró hepatomegalia y esplenomegalia leves, edema de

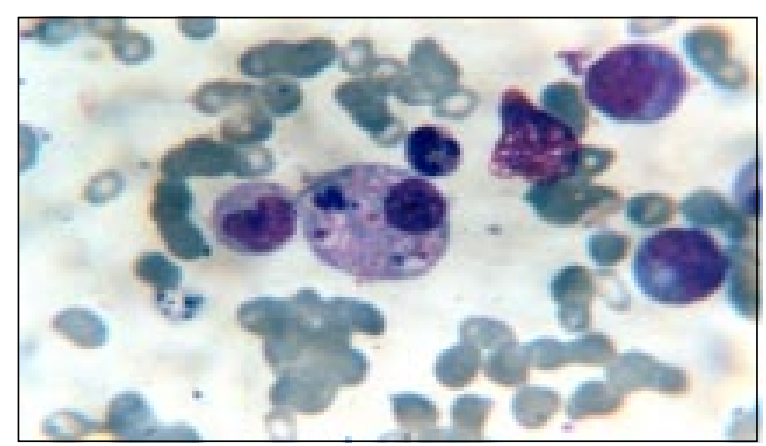

Figura 1. Caso 1: macrófago fagocitando un neutrófilo y varias plaquetas. 
pared vesicular y colecistitis acalculosa. El aspirado de médula ósea reveló hiperplasia de las series megacariocítica y mieloide, plasmocitosis medular, linfopenia medular y presencia de histiocitos fagocitando células eritroides, mieloides y plaquetas (figura 1). La IgM para dengue fue positiva. La evolución final fue buena.

\section{Caso 2}

Paciente de sexo femenino de cinco años de edad, hospitalizada del 29/01/00 al 18/02/00. Consultó por sintomatología aguda de fiebre, cefalea, osteomialgias, vómito y dolor abdominal persistente. Al realizar el examen físico, se encontró a una niña eutrófica; la prueba del torniquete fue positiva; se encontraron petequias, hemorragia subconjuntival, edemas y exantema.

La fiebre se prolongó durante 18 días; persistieron el dolor abdominal, las náuseas y, en la primera semana, el cuadro se complicó con hipotensión. Los exámenes paraclínicos mostraron un cuadro hemático con anemia leve, leucopenia, predominio de linfocitos y plaquetopenia (valor mínimo de plaquetas $85.000 / \mathrm{mm}^{3}$ ), VSG normal; el examen de gota gruesa para hemoparásitos y los antígenos febriles fueron negativos; el TPT, el examen parcial de orina normal y la radiografía de tórax fueron normales. El aspirado de médula ósea mostró médula ósea hipoplásica, hiperplasia relativa de las series megacariocítica y eritroide; se observaron histiocitos fagocitando principalmente plaquetas y algunos fagocitando eritrocitos, linfocitos y células de la serie mieloide (figura 2). La serología IgM

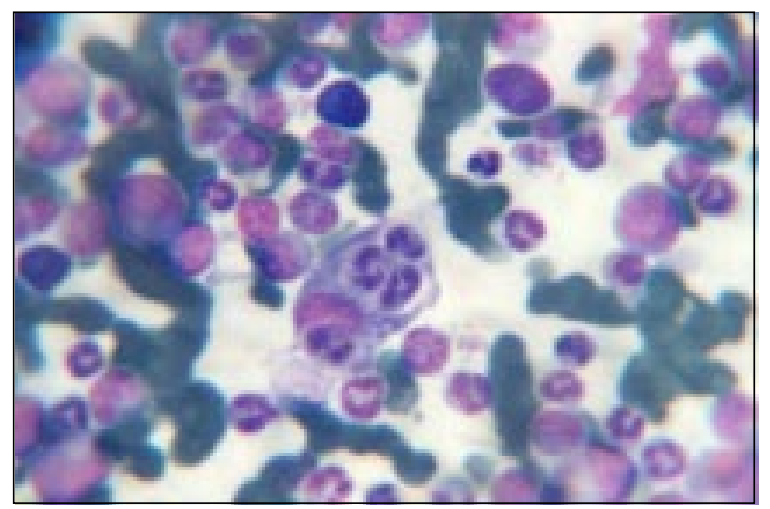

Figura 2. Caso 2: macrófago fagocitando cuatro neutrófilos. para dengue fue positiva. La evolución final con tratamiento sintomático fue buena.

\section{Caso 3}

Paciente de sexo masculino de siete años de edad, hospitalizado del 01/08/00 al 08/08/00. Consultó por sintomatología aguda de fiebre, cefalea, osteomialgias, vómito y dolor abdominal. Al hacer el examen físico, el paciente estaba eutrófico, presentaba petequias y hepatomegalia dolorosa. La fiebre se prolongó durante 14 días; persistió el dolor abdominal y en la primera semana se complicó con hipotensión. En los exámenes paraclínicos, el cuadro hemático mostró niveles de hemoglobina y hematocrito normales, leucopenia y plaquetopenia (valor mínimo de plaquetas $50.000 / \mathrm{mm}^{3}$ ). La radiografía de tórax fue normal y la ecografía abdominal mostró edema de la vescícula. El aspirado de médula ósea mostró hipoplasia de la serie eritroide, plasmocitosis medular y se vieron histiocitos fagocitando células mieloides, plaquetas y normoblastos (figura 3). La serología IgM para dengue fue positiva.También tuvo una evolución final buena con tratamiento sintomático.

En resumen, todos los pacientes fueron escolares que consultaron por sintomatología clásica de dengue (fiebre, cefalea, osteomialgias), pero llamó la atención que los tres manifestaron dolor abdominal intenso y fiebre prolongada; en el examen físico, presentaron hemorragias espontáneas, hipotensión y hepatomegalia dolorosa. Los exámenes paraclínicos mostraron plaquetopenia moderada del tercero al cuarto día

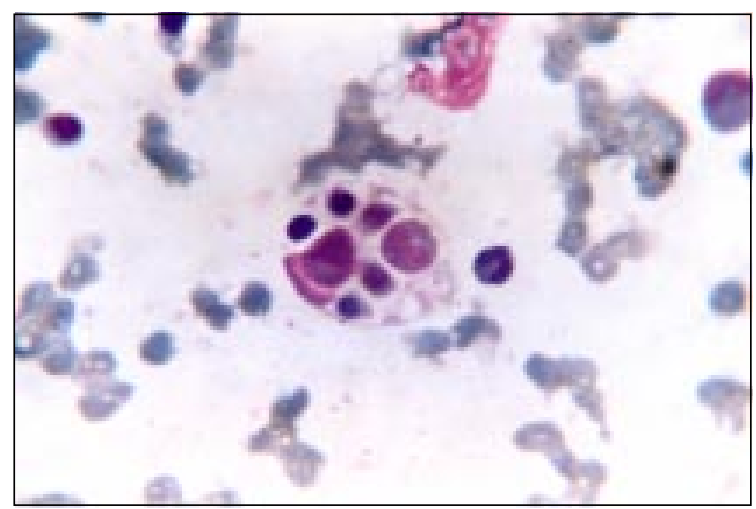

Figura 3. Caso 3: macrófago fagocitando cuatro normoblastos, un linfocito y dos células. 
Cuadro 1. Resumen de los casos.

\begin{tabular}{|c|c|c|c|}
\hline $\begin{array}{l}\text { Edad } \\
\text { Género }\end{array}$ & $\begin{array}{l}\text { Paciente } 1 \\
11 \\
\text { M }\end{array}$ & $\begin{array}{l}\text { Paciente } 2 \\
5 \\
\text { F }\end{array}$ & $\begin{array}{l}\text { Paciente } 3 \\
7 \\
\text { M }\end{array}$ \\
\hline Motivo de consulta & $\begin{array}{l}\text { Fiebre, cefalea, } \\
\text { osteomialgia, vómito, } \\
\text { dolor abdominal }\end{array}$ & $\begin{array}{l}\text { Fiebre, cefalea, } \\
\text { osteomialgia, vómito, } \\
\text { dolor abdominal }\end{array}$ & $\begin{array}{l}\text { Fiebre, cefalea, } \\
\text { osteomialgia, vómito, } \\
\text { dolor abdominal }\end{array}$ \\
\hline Examen físico & $\begin{array}{l}\text { Petequias, epistaxis, } \\
\text { torniquete positivo, } \\
\text { hepatomegalia dolorosa }\end{array}$ & $\begin{array}{l}\text { Petequias, epistaxis, } \\
\text { torniquete positivo, } \\
\text { Hepatomegalia dolorosa }\end{array}$ & $\begin{array}{l}\text { Petequias, epistaxis, } \\
\text { torniquete positivo, } \\
\text { hepatomegalia dolorosa }\end{array}$ \\
\hline Evolución & $\begin{array}{l}\text { Fiebre prolongada, } \\
\text { hipotensión, } \\
\text { dolor abdominal }\end{array}$ & $\begin{array}{l}\text { Fiebre prolongada, } \\
\text { hipotensión, } \\
\text { dolor abdominal }\end{array}$ & $\begin{array}{l}\text { Fiebre prolongada, } \\
\text { hipotensión, } \\
\text { dolor abdominal }\end{array}$ \\
\hline Cuadro hemático & $\begin{array}{l}\text { Anemia leve, } \\
\text { leucocitosis, neutrofilia }\end{array}$ & $\begin{array}{l}\text { Anemia leve, } \\
\text { leucopenia, linfocitosis }\end{array}$ & Leucopenia, linfocitosis \\
\hline Recuento plaquetario & $<85.000$ & $<85.000$ & $<85.000$ \\
\hline Ecografía abdominal & Colecistitis acalculosa & Colecistitis acalculosa & \\
\hline Serología IgM para dengue & Positiva & Positiva & Positiva \\
\hline Aspirado de medula ósea & $\begin{array}{l}\text { Histiocitos fagocitan } \\
\text { células eritroides, } \\
\text { mieloides y plaquetas }\end{array}$ & $\begin{array}{l}\text { Histiocitos fagocitan } \\
\text { células eritroides, } \\
\text { mieloides y plaquetas }\end{array}$ & $\begin{array}{l}\text { Histiocitos fagocitan } \\
\text { células eritroides, } \\
\text { mieloides y plaquetas }\end{array}$ \\
\hline
\end{tabular}

de la enfermedad que rápidamente ascendió hasta valores normales; hubo anemia leve en dos pacientes y moderada en uno, con leucopenia en dos pacientes. En los dos pacientes a quienes se les realizó ecografía abdominal, mostró colecistitis acalculosa, lo cual puede explicar la intensidad del dolor abdominal. En todos los aspirados de médula ósea se encontraron histiocitos fagocitando células hemáticas de la serie eritroide, mieloide o plaquetaria. Todos los casos fueron confirmados en el Laboratorio Departamental con serología IgM para dengue (cuadro 1).

\section{Discusión}

Se define el síndrome hemofagocítico como un conjunto de entidades clínicopatologicas, cuyo hallazgo principal es la fagocitosis de células sanguíneas por histiocitos. El síndrome está caracterizado por proliferación histiocítica con fagocitosis de células hemáticas que ocasionan diferentes grados de citopenias y se acompañan de hepatoesplenomegalia, fiebre y linfadenopatía (6-10).

En cuanto a la clasificación, los histiocitos forman parte del linaje monocito-macrófago-histiocito. Las histiocitosis son un grupo de desórdenes que tienen en común la proliferación y acumulación de macrófagos y células dendríticas. De acuerdo con la Sociedad Internacional de Histiocitosis (11), estas enfermedades se clasifican en 3 grandes grupos:

- clase I o desórdenes relacionados con células dendríticas o presentadoras de antígenos, cuya principal representante es la histiocitosis de células de Langerhans;

- clase II o desórdenes relacionados con los macrófagos o células presentadoras de antígenos, en los que se encuentran la linfohistiocitosis hemofagocítica familiar o primaria y los síndromes hemofagociticos secundarios a diversas entidades;

- clase III que corresponde a la histiocitosis maligna $(6-8,11)$.

Los tres casos presentados corresponden a la clase II y más específicamente al síndrome hemofagocítico secundario.

El síndrome hemofagocítico secundario ha sido informado asociado con infecciones virales principalmente por virus Epstein Barr (12-16), aunque también hay informes con herpes simple 
(17), herpes virus-6 (18), varicela zóster $(15,17)$, parvovirus B19 (19-21), adenovirus (17), sarampión (22), citomegalovirus y rubéola $(15,17)$, enterovirus $(23)$, virus sincitial respiratorio $(15,17)$, virus de la hepatitis B y C (24) y VIH (25); se ha informado en pocas oportunidades asociado con virus del dengue $(3,4)$.

Entre las infecciones bacterianas asociadas a este síndrome se encuentran Salmonella typhi (26), Brucella (27) y Mycobacterium tuberculosis (9). También se han informado casos de hemofagocitosis en presencia de enfermedades parasitarias como la toxoplasmosis (9) y la leishmaniosis sistémica $(15,28)$, Rickettsias e infecciones micóticas (15).

Además, se han encontrado casos de síndrome hemofagocítico secundario a la administración de drogas como la fenitoína, a la nutrición parenteral, y a los desórdenes autoinmunes $(9,29)$.

Finalmente, se han informado casos de enfermedades malignas con hemofagocitosis secundarias especialmente asociadas con linfomas, leucemias e histiocitosis de células de Langerhans $(9,15,30)$.

Es necesario hacer una diferenciación entre los síndromes hemofagocíticos familiares o primarios y los síndromes hemofagocíticos secundarios. En la histiocitosis familiar, la evolución es rápida y progresiva con aparición de linfadenopatías generalizadas, disfunción hepática, desórdenes de la coagulación y anormalidades del sistema nervioso central. El síndrome hemofagocítico secundario es adquirido y reversible; generalmente desaparece una vez se controla la causa desencadenante. Los hallazgos clínicos son muy similares en ambos síndromes y el diagnóstico se basa en la presencia de hemofagocitosis en la médula ósea o en otros órganos del sistema monocito-macrófago. A nivel periférico, se requiere la presencia de citopenia, por los menos, de dos líneas celulares. Mientras que el síndrome hemofagocítico primario se manifiesta en edades muy tempranas, el secundario puede aparecer en cualquier edad. En lactantes menores es muy difícil diferenciarlos y no hay criterios clínicos o patológicos para establecer diferencias entre la linfohistiocitosis hemofagocítica primaria y la secundaria, aunque se logre la identificación de un organismo infeccioso causal. Posiblemente, la única diferencia real es que en la primaria hay deficiencia en la función de las células naturales asesinas, lo cual no se encuentra en la secundaria $(8,9,15)$.

La hemofagocitosis secundaria ha sido descrita en inmunosuprimidos en asociación con huéspedes con infecciones virales. Los tres casos que informamos en este estudio se refieren a pacientes con dengue hemorrágico comprobado por serología, quienes en el curso de su enfermedad tuvieron una evolución atípica, con la fiebre prolongada como el signo más constante, lo cual nos obligó a realizar un aspirado de médula ósea como parte de la investigación del diagnóstico diferencial. El principal sitio de replicación del virus del dengue se cree que son las células de linaje mononuclear fagocítico, ya que se han detectado antígenos virales en monocitos obtenidos de riñón, piel, hígado, bazo, timo, pulmón y saliva (31).

Marianneau y colaboradores describieron el gran número de sitios de replicación viral (32) y además, comprobaron que los casos fatales de dengue hemorrágico no se pueden explicar solamente por la muerte celular sino que existe una serie de disturbios metabólicos que contribuyen a la destrucción tisular. Ellos demostraron que la replicación del virus del dengue en células infectadas lleva a la muerte celular apoptótica tanto in vitro como in vivo. Estos autores concluyen que la eliminación de los cuerpos apoptóticos por las células fagocíticas es una forma de depuración del virus del dengue desde los tejidos infectados; sin embargo, los mecanismos de defensa del huésped, que comprenden la apoptosis y la activación celular fagocítica, pueden causar injuria tisular local o inbalance homeostático transitorio y pueden disparar eventos deletéreos posteriores. Este mecanismo podría explicar la presentación del síndrome hemofagocítico en el dengue hemorrágico.

\section{Conclusiones}

En los niños que tengan diagnóstico de dengue hemorrágico y cuyo curso clínico sea atípico 
(fiebre prolongada, dolor abdominal persistente y citopenias) se debe practicar un aspirado de médula ósea para descartar una enfermedad linfoproliferativa y por la posibilidad de que la causa de la complicación corresponda a un síndrome hemofagocítico secundario. Esta entidad no requiere ningún tratamiento específico diferente a las medidas de soporte que necesite el paciente según los signos y síntomas que presente.

En este trabajo asumimos que el síndrome hemofagocítico secundario es el responsable de los síntomas que en determinado momento prolongan o complican el dengue hemorrágico; sin embargo, sería interesante realizar una investigación prospectiva para determinar si en otros casos de fiebre hemorrágica por dengue (aún en los casos no complicados) se presenta hemofagocitosis y, además, que sea útil para describir los hallazgos medulares más constantes en dicha enfermedad.

\section{Referencias}

1. George R, Lum LC. Clinical spectrum of dengue infection. En: Gubler DJ, Kuno G, editors. Dengue and dengue hemorrhagic fever. Wallingford, UK: CAB International; 1997. p.89-113.

2. González G, Méndez A. Dengue: espectro clínico. Tribuna Medica 1998;99:203-18.

3. Ramanathan M, Duraisamy G. Haemophagocytosis in dengue haemorrhagic fever: a case report. Ann Acad Med Singapore 1991;20:803-4.

4. Djossou F, Malvy D, Delbrel X, Germain P, Etienne $\mathbf{G}$, Longy-Boursier $\mathbf{M}$, et al. Haemophagocytosis in dengue fever: a case report. Proceedings of the XV International Congress for Tropical Medicine and Malaria; 2000, August 20-26; Cartagena, Colombia; 2000. p.126.

5. Ocaziones R, Alvarez A, Cortés F, Fábregas R. Reappearance of dengue-3 virus in Colombia. Emerg Infect Dis 2002 (en prensa).

6. Ladisch S, Jaffe ES. The histiocytosis. En: Pizzo PA, Poplack DG, editors. Principles and practice of pediatric oncology. Third Edition. Philadelphia: Lippincott Raven Publishers;1997. p.615-31.

7. Lanzkowsky P. Histiocytosis sindromes. En: Lanzkowsky $P$, editor. Manual of pediatric hematology and oncology. Second edition. New York: Churchill Livinsgstone; 1995. p.493-511.

8. Henter J, Arico M, Elinder G, Imashuku S, Janka G. Familial hemophagocytic lymphohistiocytosis. Hematol Oncol Clin North Am 1998;2:417-33.
9. Gauvin F, Toledano B, Champagne J, Lacroix J. Reactive hemophagocytic syndrome presenting as a component of multiple organ dysfunction syndrome. Critical Care Medicine 2000;28:3341-5.

10. Qari M, Roberts GT. Improving the diagnostic precision of bone marrow examination for hemophagocytic syndromes. Laboratory Hematology 1999;5:37-42.

11. Writing Group of the Histiocyte Society. Histiocytosis syndromes in children. Lancet 1987;1: 208-9.

12. Dreyer ZE, Dowell BL, Chen H, Hawkins E, McClain KL. Infection-associated hemophagocytic syndrome. Evidence for Epstein-Barr virus gene expression. Am J Pediatr Hematol Oncol 1991;13:476-81.

13. Yatabe Y, Mori N, Oka K, lijima T, Saga S, Takada K, et al. Fatal Epstein-Barr virus-associated lymphoproliferative disorder in childhood. Arch Pathol Lab Med 1995; 119:409-17.

14. Okano M, Gross TG. Epstein-Barr virus-associated hemophagocytic syndrome and fatal infectious mononucleosis. Am J Hematol 1996;53:111-5.

15. Gritta J, Imashuku S, Elinder G, Schneider M, Henter J. Infection and malignancy associated hemophagocytic syndromes. Hematol Oncol Clin North Am 1999;12:43544.

16. Sotto A, Bessis D, Porneuf M, Taib J, Ciurana AJ, Jourdan J. Syndrome of hemophagocytosis associated with infections. Pathol Biol (Paris) 1994;42:861-7.

17. Risdall RJ, McKenna RW, Nesbit ME, Krivit W, Balfour HH Jr, Simmons RL, Brunning RD. Virus-associated hemophagocytic syndrome: a benign histiocytic proliferation distinct from malignant histiocytosis. Cancer 1979;44:993-1002.

18. Takagi M, Unno A, Maruyama T, Kaneko K, Obinata K. Human herpesvirus-6 (HHV-6)-associated hemophagocytic syndrome. Pediatr Hematol Oncol 1996;13:451-6.

19. Mustafa MM, McClain KL. Diverse hematologic effects of parvovirus B19 infection. Pediatr Clin North Am 1996; 43:809-21.

20. Syruckova Z, Stary J, Sedlacek P, Smisek P, Vavrinec J, Komrska V, et al. Infection-associated hemophagocytic syndrome complicated by infectious lymphoproliferation: a case report. Pediatr Hematol Oncol 1996;13:143-50.

21. Muir K, Todd WT, Watson WH, Fitzsimons E. Viralassociated haemophagocytosis with parvovirus-B19related pancytopenia. Lancet 1992;339:1139-40.

22. Komatsuda A, Chubachi A, Miura AB. Virusassociated hemophagocytic syndrome due to measles accompanied by acute respiratory failure. Intern Med 1995;34:203-6. 
23. Barre V, Marret S, Mendel I, Lesesve JF, Fessard CI. Enterovirus-associated haemophagocytic syndrome in a neonate. Acta Paediatr 1998;87:469-71.

24. Faurschou M, Nielsen OJ, Hansen PB, Juhl BR, Hasselbalch $\mathbf{H}$. Fatal virus-associated hemo-phagocytic syndrome associated with coexistent chronic active hepatitis $B$ and acute hepatitis $C$ virus infection. Am J Hematol 1999;61:135-8.

25. Pellegrin JL, Merlio JP, Lacoste $D$, Barbeau $P$, Brossard G, Beylot J, et al. Syndrome of macrophagic activation with hemophagocytosis in human immunodeficiency virus infection. Rev Med Interne 1992;13:438-40

26. Pereira F, Manrique LA, Restrepo C, Roa J. Síndrome hemofagocítico en fiebre tifoidea. Acta Pediátrica Colombiana 1983;1:15-7.

27. al-Eissa Y, al-Nasser M. Haematological manifestations of childhood brucellosis. Infection 1993;21:23-6.
28. Gagnaire MH, Calambrun C, Stephan JL. Hemophagocytic syndrome: a misleading complication of visceral leishmaniasis in children. A series of 12 cases. Pediatrics 2000;106:E58.

29. Ohga S, Ooshima A, Fukushige J, Ueda K. Histiocytic haemophagocytosis in a patient with Kawasaki disease: changes in the hypercytokinaemic state. Eur J Pediatr 1995; 154:539-41.

30. Klein A, Corazza F, Demulder A, Van Beers D, Ferster A. Recurrent viral associated hemophagocytic syndrome in a child with Langerhans cell histiocytosis. J Pediatr Hematol Oncol 1999;21:554-6.

31. Isturiz RE, Gubler D, Brea J. Dengue and dengue hemorrhagic fever in Latin America and the Caribbean. Infect Dis Clin North Am 2000;14:121-40.

32. Marianneau P, Flamand $\mathbf{M}$, Deubel V, Despres $\mathbf{P}$. Apoptotic cell death in response to dengue virus infection: the pathogenesis of dengue haemorrhaegic fever revisited. Clin Diagn Virol 1998;10:113-9. 